\title{
Dacron conduit with a stented porcine xenograft valve in the anatomic correction of transposition of the great arteries and subpulmonary stenosis
}

\author{
LORENZO GONZALEZ-LAVIN and ALBERT W. SPARROW \\ Divisions of Cardiothoracic Surgery and Paediatric Cardiology, College of Human Medicine, \\ Michigan State University, East Lancing, Michigan 48824, USA
}

\begin{abstract}
Gonzalez-Lavin, L. and Sparrow, A. W. (1975). Thorax, 30, 644-649. Dacron conduit with a stented porcine xenograft valve in the anatomic correction of transposition of the great arteries and subpulmonary stenosis. A stented porcine xenograft valve, sutured into a woven Dacron tubular graft, has been used in the anatomic correction of D-loop, D-transposition of the great arteries, and subpulmonary stenosis. The main advantage of this technique is its simplicity and practicality, as both Dacron tubular grafts and stented porcine xenograft valves are commercially available.
\end{abstract}

Since anatomic correction of transposition of the great arteries associated with left ventricular outflow tract obstruction became feasible (Rastelli, 1969; Rastelli, Wallace, and Ongley, 1969b; McGoon Wallace, and Danielson, 1973) the long-term prognosis of patients having this anomaly has been greatly improved. Concurrent with the wide clinical application of this procedure, late complications inherent in the use of preserved aortic homografts have recently been encountered (Merin and McGoon, 1973; McGoon, 1973; Park et al., 1973).

As the repair proposed by Rastelli is based on firm anatomical grounds (Rastelli, McGoon, and Wallace, 1969a) a search for some other type of valve-bearing conduit between the right ventricle and pulmonary artery is justified. The purpose of this communication is to report the use of a Dacron conduit with a stented porcine xenograft valve in the anatomic correction of two patients with D-loop, D-transposition of the great arteries and subpulmonary stenosis.

\section{CASE REPORTS}

CASE 1 A 15-year-old white girl had had cyanosis and a heart murmur since birth. Cardiac catheterization had been performed at the age of 9 days, and again at 4 years, and a diagnosis of transposition of the great arteries with subpulmonary stenosis was made. Because of severe cyanosis and failure to thrive, a left subclavian artery to pulmonary artery anastomosis was performed when she was 5 years old. Her clinical condition remained stable until one year before her latest admission when she developed breathlessness, tiredness, and increased cyanosis. In 1973 a further cardiac catheterization and angiography confirmed the diagnosis of D-loop, $\mathbf{D}$ transposition of the greatarteries with combined bilateral conus, ventricular and atrial septal defects, and subpulmonary stenosis. Total correction was advised and she was admitted for elective surgery.

Physical examination revealed a young active white girl with severe cyanosis, moderately overweight, blood pressure $120 / 80 \mathrm{mmHg}$ and regular pulse of 70 per minute. The pertinent physical findings were confined to the precordium. Heart rhythm was regular with a normal first heart sound; the second sound was single. There was an ejection click followed by an ejection systolic murmur, grade IV/VI, at the left sternal border. A continuous murmur, machinerylike, was present in the left subclavicular area. Radiographs of the chest showed a right-sided aortic arch; the cardiac configuration was compatible with transposition of the great vessels. The lung fields were clear with decreased pulmonary vasculature. An electrocardiogram showed sinus rhythm and right ventricular hypertrophy.

In preparation for surgery, repeated phlebotomies to a total of $1400 \mathrm{ml}$ were required to bring her coagulogram within normal limits (Fig. 1). On 20 June 1973 the patient was taken to the operating room. Through a midline incision the heart was exposed. In addition to transposition of the great vessels with subpulmonary stenosis, there was left juxtaposition of the atrial appendages. While preparations for cardiopulmonary bypass were in 


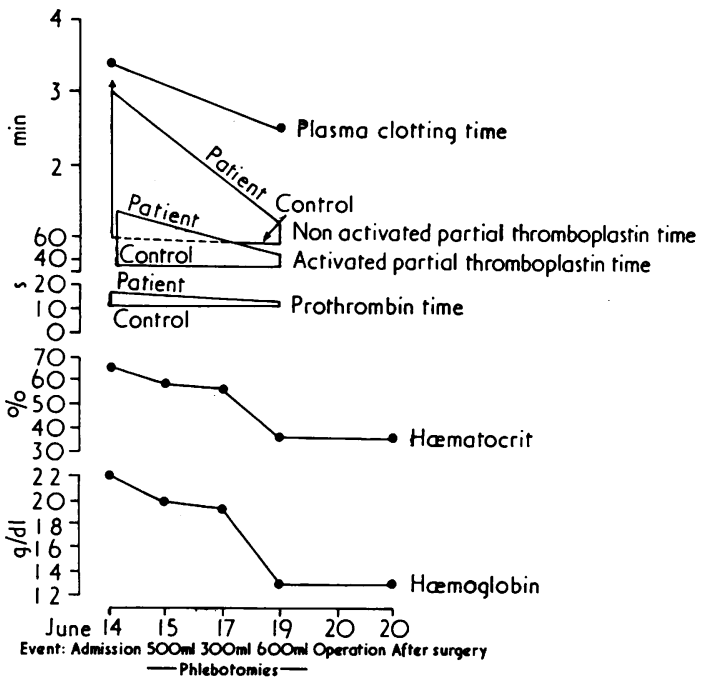

FIG. 1. Reversion of coagulation studies to within normal limits after repeated phlebotomies.

progress, a $21 \mathrm{~mm}$ stented porcine xenograft valve (Hancock Labs, Inc, 4633 E. LaPalma Avenue, Anaheim, California 92807) was sutured into the lower third of a $23 \mathrm{~mm}$ woven Dacron tubular graft (Woven Dacron Seamless Tubular Graft, USCI, Glens Falls, New York 12801) (Figs. 2 and 3).

Dissection and control of the previous Blalock anastomosis was performed before institution of cardiopulmonary bypass. An oblique right ventricul-

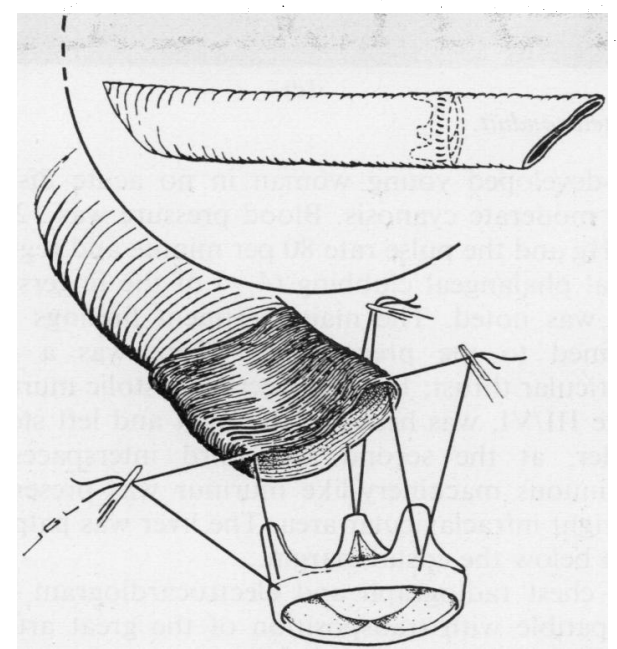

FIG. 2. Technique for construction of composite conduit. The lower third of the Dacron tubular graft is folded back and the stented xenograft valve is sutured into the graft with a running suture interrupted at each commissure. otomy was then made and the intracardiac anatomy exposed. A large subaortic ventricular septal defect, $3 \times 4 \mathrm{~cm}$ in its largest diameter, was found. Through the defect the left ventricular outflow tract was visualized and found to be severely narrowed by hypertrophy of the conus, forming a well-defined ring of myocardium. There was no fibrous continuity between the mitral and aortic valves. The pulmonary ring was severely hypoplastic, measuring less than $8 \mathrm{~mm}$ in diameter. The infundibulum of the right ventricle was formed by a well-developed muscular ring consisting of the crista supraventricularis together with its parietal and septal bands and the moderator band. This anatomy was favourable for the use of an oval-shaped Dacron patch to redirect the blood flow from the left ventricle through the ventricular septal defect into the ascending aorta. The patch was secured in place with interrupted sutures of 3-0 Tevdek. The main pulmonary artery was tied off at its origin and a longitudinal incision, $25 \mathrm{~mm}$ in length, was made distal to the ligature. The previously prepared graft was used as a valvular conduit to establish continuity between the right ventricle and the pulmonary artery. The graft was first sutured to the right ventricular incision with a running stitch of 4-0 Tevdek; the distal end of the graft was then sutured to the main pulmonary artery, end-to-side in the same fashion. The right atrium was opened and a large atrial septal defect was closed with a pericardial patch. After completion of the repair intraoperative pressure measurements were: left ventricle, $110 / 12 \mathrm{mmHg}$; right ventricle, $45 / 10$ $\mathrm{mmHg}$; pulmonary artery, $40 / 15 \mathrm{mmHg}$; left atrium (mean) $15 \mathrm{mmHg}$. The completed repair is shown in Figure 4. The patient's postoperative course was uneventful.

When last seen, 30 months after operation, she was found to be asymptomatic and was going to school full-time. Her blood pressure was $110 / 80 \mathrm{mmHg}$. There was a soft systolic ejection murmur, II/VI, at the right sternal border with a good closing sound of the xenograft valve. An electrocardiogram showed a lesser degree of right ventricular hypertrophy. A chest radiograph showed the heart shadow within normal limits and normal vascularity of both lung fields. On restudy 15 months after correction, a right ventricular angiocardiogram showed a wellpositioned conduit with unimpeded blood flow (Fig. 5).

CASE 2 A 24-year-old white woman had been cyanotic at birth and was known to have a heart murmur. At the age of 3 years she developed spinal meningitis and a brain abscess that was surgically drained. Jacksonian seizures were well controlled with Dilantin and phenobarbital. 


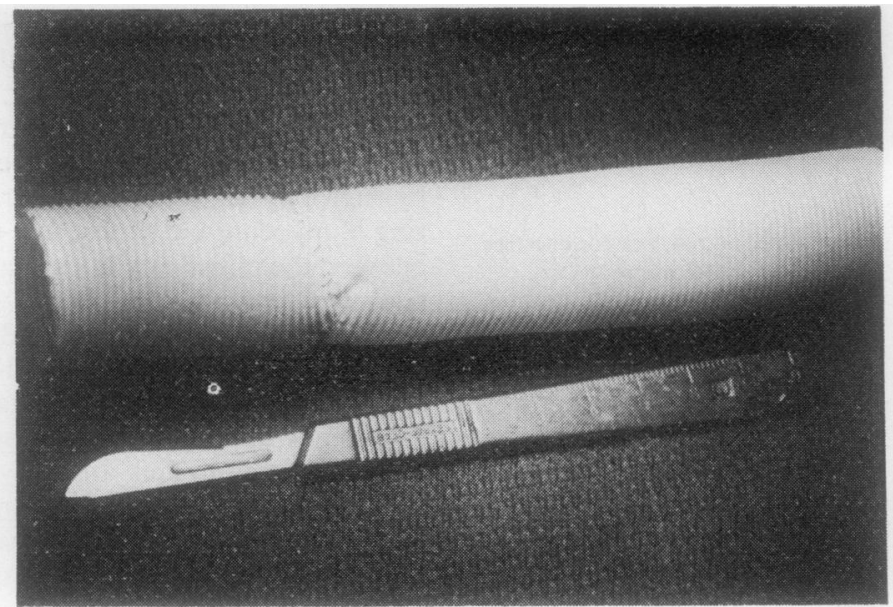

(a)

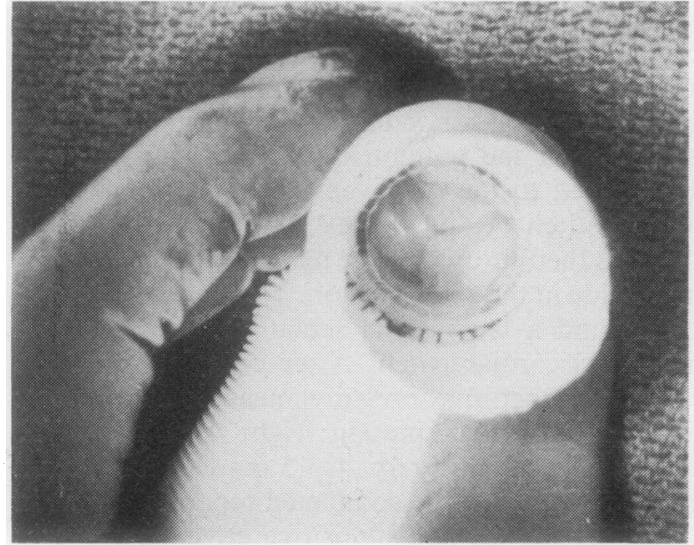

(b)

FIG. 3. (a-c) The completed conduit.

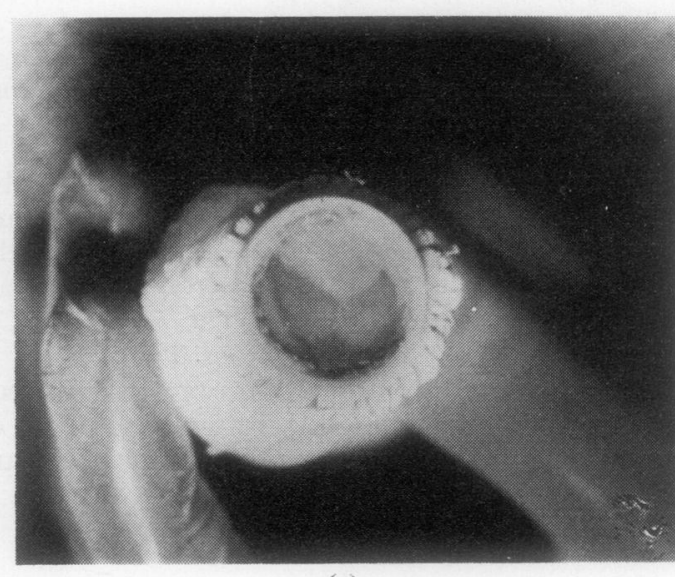

(c)
Cardiac catheterization was first performed at seven years of age and a diagnosis of transposition of the great arteries with pulmonary stenosis was established. Because of increasing symptomatology, she was again catheterized in 1962 at age 13, and a right Blalock-Taussig shunt was performed. Her clinical condition improved enough to allow her to indulge in some physical activities; however, her limitations caused her to seek further assessment and she was admitted for investigation in January 1974.

Cardiac catheterization and angiography confirmed the diagnosis of D-loop, D-transposition of the great arteries with combined bilateral conus, subpulmonary stenosis, and a subaortic restrictive ventricular septal defect. Total correction was advised and she was admitted for elective surgery in June 1974.

On admission physical examination revealed a well-developed young woman in no acute distress with moderate cyanosis. Blood pressure was 120/70응 $\mathrm{mmHg}$ and the pulse rate 80 per minute and regular. Distal phalangeal clubbing $(4+)$ of the fingers and은 toes was noted. The main pertinent findings were confined to the precordium. There was a right ventricular thrust, $1+$. An ejection systolic murmur, N grade III/VI, was heard at the right and left sternalborder, at the second and third interspaces. $A$ O continuous machinery-like murmur was present in w the right infraclavicular area. The liver was palpable $2 \mathrm{~cm}$ below the costal margin.

A chest radiograph and electrocardiogram were compatible with transposition of the great arteries? and left ventricular outflow tract obstruction. Coagulation profiles were within normal limits.

Operation was performed through a mid-line incision. The external appearance of the heart was $\stackrel{\mathbb{Q}}{\mathbb{Q}}$ 


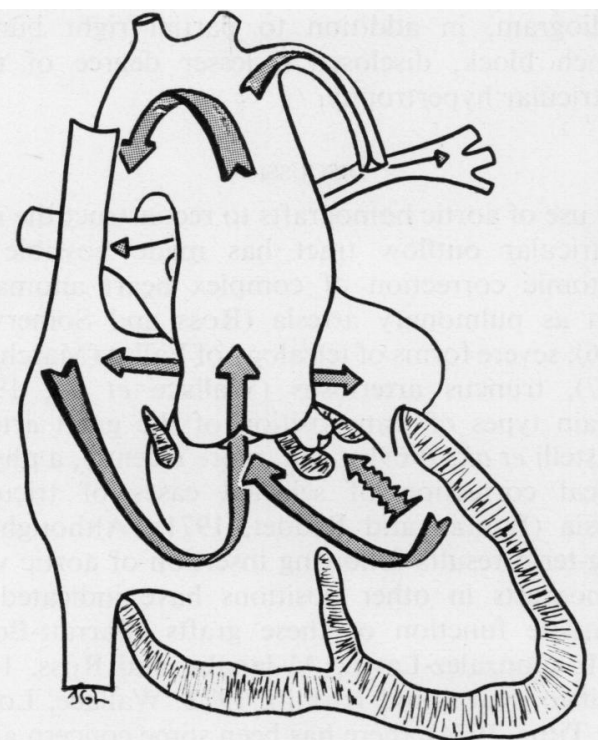

(a)

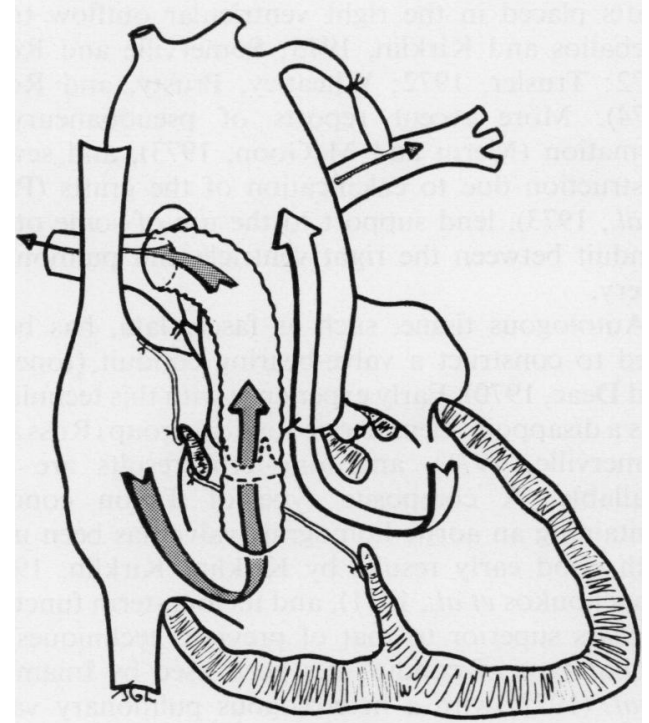

(b)

FIG. 4. Blood flow (a) before and (b) after anatomical correction.

that of transposition of the great arteries. Dissection and control of the previous Blalock anastomosis was performed. The patient was placed on cardiopulmonary bypass with moderate hypothermia to $28^{\circ} \mathrm{C}$. An oblique right ventriculotomy was performed and a circumference of anterior ventricular muscle was excised. A restrictive ventricular septal defect was located immediately beneath the aortic valve.

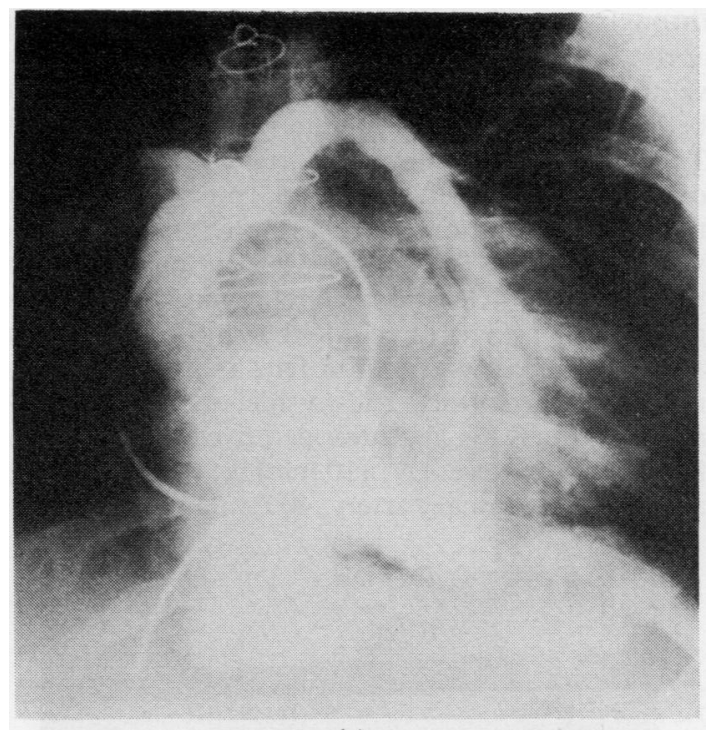

(a)

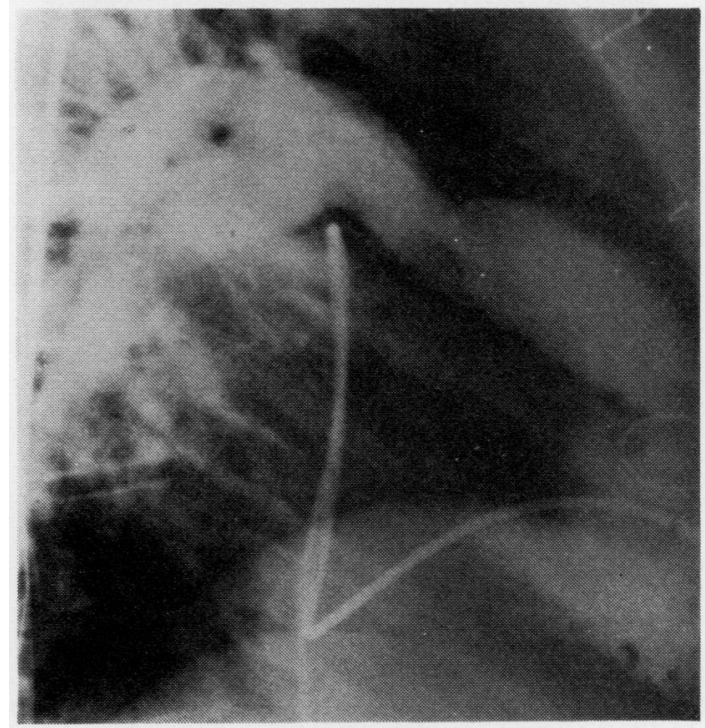

(b)

FIG. 5. Case 1. Right ventricular angiocardiogram 15 months after correction showing conduit with unimpeded blood flow: (a) anteroposterior view; (b) lateral view.

There was no fibrous continuity between the mitral and aortic valves. A subpulmonary conus was present, and the pulmonary artery annulus was extremely small, about $6 \mathrm{~mm}$ in greatest diameter. The ventricular septal defect was enlarged anteriorly to equal the size of the aortic annulus. A Dacron patch was used to re-route the blood flowing from the left ventricle 
through the ventricular septal defect and into the aorta. The patch was attached to the edges of the ventricular septal defect and the infundibular muscle below the aortic valve with interrupted stitches of 3-0 Tevdek. The main pulmonary artery was tied off at its origin. A previously prepared, preclotted $25 \mathrm{~mm}$ tubular graft containing a $21 \mathrm{~mm}$ stented porcine valve was then used to establish continuity between the right ventricle and the pulmonary artery. The proximal end was sutured into the ventricular incision and re-inforced with Teflon felt; the distal anastomosis was performed end-to-side to the main pulmonary artery (Fig. 6). Intraoperative pressures taken before closure were: $\mathrm{LV}, 110 \mathrm{mmHg}$; RV, $50 \mathrm{mmHg}$; and distal pulmonary artery, $40 \mathrm{mmHg}$.

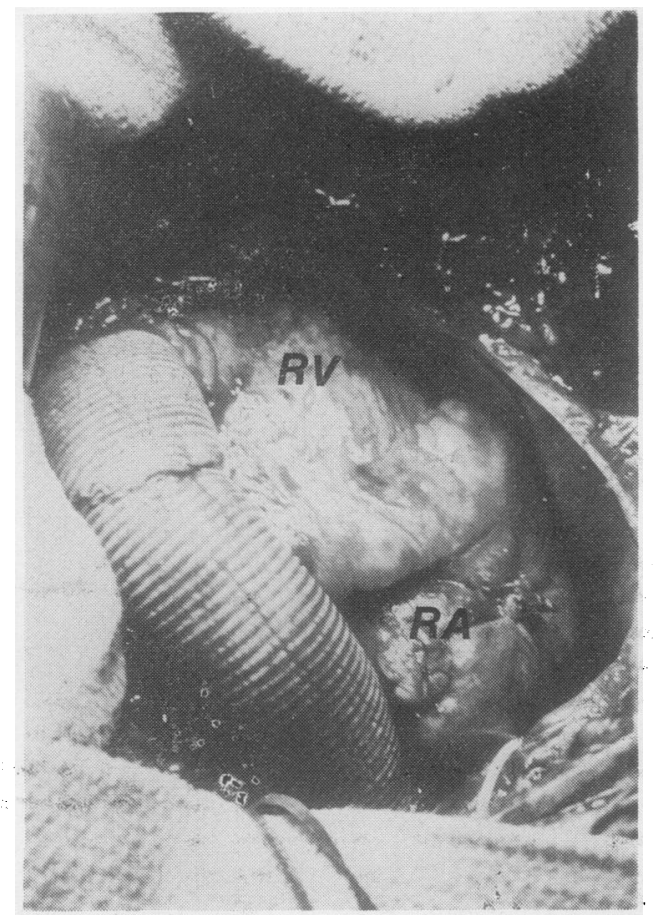

FIG. 6. A view from the head of the operating table showing the conduit in place: $R V=$ right ventricle; $R A=$ right atrium.

The patient's postoperative course was smooth except for the development of a left pleural effusion requiring thoracentesis. When last seen, 15 months after operation, the patient was completely asymptomatic and fully active. The blood pressure was $120 / 80 \mathrm{mmHg}$. There was a soft ejection murmur, II/VI, at the left sternal border with a good closing sound of the xenograft valve. A chest film showed the heart shadow to be within normal limits. The electro- cardiogram, in addition to partial right bundle- $\stackrel{\vec{\sim}}{\stackrel{\vec{S}}{9}}$ branch block, disclosed a lesser degree of right ventricular hypertrophy.

\section{DISCUSSION}

The use of aortic homografts to reconstruct the right $\%$ ventricular outflow tract has made possible the $\vec{\circ}$ anatomic correction of complex heart anomalies, $\vec{\overrightarrow{ }}$ such as pulmonary atresia (Ross and Somerville, $\vec{\sigma}$ 1966), severe forms of tetralogy of Fallot (Marchand, $\overrightarrow{\vec{F}}$ 1967), truncus arteriosus (Wallace et al., 1969), $\times$ certain types of transposition of the great arteries ${ }^{\omega}$ (Rastelli et al., 1969b), and, more recently, a physio- $\dot{\sigma}$ logical correction of selected cases of tricuspid $\stackrel{\circ}{+}$ atresia (Fontan and Baudet, 1971). Although the long-term results following insertion of aortic valve $\frac{}{5}$ homografts in other positions have indicated the $\vec{\square}$ adequate function of these grafts (Barratt-Boyes, $\mathbb{D}$ 1971; Gonzalez-Lavin, Al-Janabi, and Ross, 1972; 尽 Pacifico, Karp, and Kirklin, 1972; Wallace, Londe, 흠 and Titus, 1974), there has been some concern about $\stackrel{\mathbb{\Phi}}{\stackrel{1}{-}}$ the high incidence of early calcification among those $\vec{v}$ grafts placed in the right ventricular outflow tract (Ceballos and Kirklin, 1973; Somerville and Ross, 1972; Trusler, 1972; Wheatley, Prusty, and Ross, 1974). More recent reports of pseudoaneurysm formation (Merin and McGoon, 1973), and severe obstruction due to calcification of the grafts (Park $\frac{\varnothing}{\varnothing}$ et al., 1973), lend support to the use of some other $\cong$ conduit between the right ventricle and pulmonary $\overrightarrow{\hat{O}}$ artery.

Autologous tissue, such as fascia lata, has been used to construct a valve-bearing conduit (Ionescu? and Deac, 1970). Early experience with this technique was a disappointment to one surgical group (Ross and $\frac{\mathrm{O}}{7}$ Somerville, 1971), and long-term results are not $\times$ available. A composite type of Teflon conduit 윽 containing an aortic homograft valve has been used: with good early results by Kirklin (Kirklin, 1973; 응 Kouchoukos et al., 1971), and its long-term function appears superior to that of previous techniques. $\mathrm{A}$ 음 similar type of conduit has been used by Imamura $D$ et al. (1972) with a heterologous pulmonary valve? with a Dacron tubular graft.

A modification of these concepts was used in our cases; a frame-mounted porcine xenograft was 0 sutured into the lower third of a woven Dacronw tubular graft. The practicalities of the conduit are the commercial availability of its components, and theo simplicity of its construction and insertion. Dacron $₫$ grafts permit a precise tailoring and positioning of the ${ }^{?}$ conduit to avoid acute angulations. An end-to-side믐 distal anastomosis facilitates as large a conduit as possible into the hypoplastic pulmonary artery. The incorporation of a stented porcine xenograft valve $\stackrel{\mathbb{Q}}{\circ}$ 
assures proper position and function of a nonthrombogenic valve without problems of distortion in addition to offering a good, effective valve orifice.

\section{REFERENC ES}

Barratt-Boyes, B. G. (1971). Long-term follow-up of aortic valvular grafts. British Heart Journal, 33, Supplement, p. 60.

Ceballos, R. and Kirklin, J. W. (1973). Long-term anatomical results of intracardiac repair of tetralogy of Fallot. Annals of Thoracic Surgery, 15, 371.

Fontan, F. and Baudet, E. (1971). Surgical repair of tricuspid atresia. Thorax, 26, 240.

Gonzalez-Lavin, L., Al-Janabi, N., and Ross, D. N. (1972). Long-term results after aortic valve replacement with preserved aortic homografts. Annals of Thoracic Surgery, 13, 594.

Imamura, E. S., Konno, S., Arai, T., and Sakakibara, S. (1972). Composite graft of heterologous pulmonary valve and prosthetic tube for the reconstruction of right ventricular outflow tract: clinical application in four patients. Journal of Thoracic and Cardiovascular Surgery, 63, 747.

Ionescu, M. I. and Deac, R. C. (1970). Fascia lata composite graft for right ventricular outflow tract and pulmonary artery reconstruction. Thorax, 25, 427.

Kirklin, J. W. (1973). Surgical treatment of patients with absence of direct anatomic continuity between pulmonary arterial system and the heart and ventricular septal defect. In Heart Disease in Infancy: Diagnosis and Surgical Treatment, edited by B. G. Barratt-Boyes, J. M. Neutze, and E. A. Harris, p. 211. Churchill Livingstone, Edinburgh.

Kouchoukos, N. T., Barcia, A., Bargeron, L. M., and Kirklin, J. W. (1971). Surgical treatment of congenital pulmonary atresia with ventricular septal defect. Journal of Thoracic and Cardiovascular Surgery, 61, 70.

Marchand, P. (1967). The use of cusp-bearing homograft patch to the outflow tract and pulmonary artery in Fallot's tetralogy and pulmonary valvular stenosis. Thorax, 22, 497.

McGoon, D. C. (1973). Complex congenital malformations: Surgery for transposition of the great arteries with ventricular septal defect and pulmonary stenosis. Advances in Cardiovascular Surgery, edited by J. W. Kirklin, p. 83, Grune and Stratton, New York.

, Wallace, R. B., and Danielson, G. K. (1973). The Rastelli operation. Its indications and results. Journal of Thoracic and Cardiovascular Surgery, 65, 65.

Merin, G. and McGoon, D. C. (1973). Re-operation after insertion of aortic homograft as a right ventricular outflow tract. Annals of Thoracic Surgery, 16, 122.
Pacifico, A. D., Karp, R. B., and Kirklin, J. W. (1972). Homografts for replacement of the aortic valve. Circulation, 45 and 46 Supplement 1, pp. 1-36.

Park, S. C., Neches, W. H., Lenox, C. C., Zuberbuhler, J. R., and Bahnson, H. T. (1973). Massive calcification and obstruction in a homograft after the Rastelli procedure for transposition of great arteries. American Journal of Cardiology, 32, 860.

Rastelli, G. C. (1969). A new approach to anatomic repair of transposition of the great arteries. Mayo Clinic Proceedings, 44, 1.

_- McGoon, D. C., and Wallace, R. B. (1969a). Anatomic correction of transposition of the great arteries with ventricular septal defect and subpulmonary stenosis. Journal of Thoracic and Cardiovascular Surgery, 58, 545.

_- Wallace, R. B., and Ongley, P. A. (1969b). Complete repair of transposition of the great arteries with pulmonary stenosis: A review and report of a case corrected by using a new surgical technique. Circulation, 39, 83.

Ross, D. N. and Somerville, J. (1966). Correction of pulmonary atresia with a homograft aortic valve. Lancet, 2, 1446.

(1971). Fascia lata reconstruction of the right ventricular outflow tract. Lancet, 1, 941.

Somerville, J. and Ross, D. N. (1972). Long-term results of complete correction with homograft reconstruction in pulmonary outflow tract atresia. British Heart Journal, 34, 29.

Trusler, G. A. (1972). Use of valve-retaining homograft and heterograft patch for reconstruction of right ventricular outflow tract. In discussion of Eguchi, $S$. et al. (1972). Annals of Thoracic Surgery, 14, 615.

Wallace, R. B., Londe, S. P., and Titus, J. L. (1974). Aortic valve replacement with preserved aortic valve homografts. Journal of Thoracic and Cardiovascular Surgery, 67, 44.

Rastelli, G. C., Ongley, P. A., Titus, J. L., and McGoon, D. C. (1969). Complete repair of truncus arteriosus defects. Journal of Thoracic and Cardiovascular Surgery, 57, 95.

Wheatley, D. J., Prusty, S., and Ross, D. N. (1974). Reconstruction of right ventricular outflow with a valved homograft conduit. Thorax, 29, 617.

Requests for reprints to: Professor L. Gonzalez-Lavin, Head of Division of Cardiothoracic Surgery, Department of Surgery, Michigan State University, East Lansing, Michigan, 48824, USA. 